\title{
NOTAS DE MATEMÁTICA E FISICA: um elo entre pesquisa e ensino
}

\author{
Notes of mathematics and physics: \\ a link between research and teaching
}

Aparecida Rodrigues Silva Duarte ${ }^{1}$

\section{Resumo}

Este trabalho apresenta a Revista "Notas de Matemática e Física", publicada entre 1953 e 1954, nas dependências da Faculdade de Filosofia Ciências e Letras da Universidade de São Paulo. A revista fora produzida por alunos iniciantes do Departamento de Matemática e Física desta Instituição, os quais tinham como objetivo discutir temas que viessem a contribuir para a atualização dos conhecimentos nessas áreas, tanto para os alunos ingressantes no curso superior quanto para professores e alunos do curso secundánio. Durante o trabalho de organização do Arquivo Pessoal Ubiratan D'Ambrosio - o APUA, encontramos, dentre a massa de documentos doados, um dos fascículos dessa revista contendo um artigo do professor D'Ambrosio quando ainda estudante do Curso de Matemática. Tal achado incitou-nos a investigar a vida dessa revista, apoiando-nos especialmente em Catani (1996), partindo do pressuposto que revistas pedagógicas e científicas são fontes importantes para as pesquisas que o grupo vem realizando sobre a história da educação matemática brasileira.

Palavras-chave: História da Educação Matemática; APUA; Revistas pedagógicas.

Universidade do Vale do Sapucaí - UNIVÁS/MG

Programa de Estudos Pós-Graduados em Educação Matemática - PUC/SP - Rua Marquês de Paranaguá, 111, Consolação, São Paulo-SP, CEP 01303-050

angel-bb@uol.com.br 


\section{Abstract}

This paper presents the journal "Notes of Mathematics and Physics" published between 1953 and 1954, at "Faculdade de Filosofia, Ciências e Letras da Universidade de São Paulo". The journal was produced by students beginner from the Mathematics and Physics Department of this Institution and its main objective was to discuss themes that could contribute to update the knowledge of these fields, for high education beginner students and professors and students from high school as well. During the organization of Ubiratan D'Ambrosio's personal file - named APUA - it was found, among the donated documents, one of the fascicles of this journal containing an article of D'Ambrosio when he was a college student. Such finding motivated us investigate the life of this journal, especially based on Catani (1996), assuming that pedagogical and scientific journals are important sources for the researches that the group have been developing about the History of the Brazilian Mathematical Education.

Keywords: History of Mathematics Education; APUA; Pedagogical journals.

\section{Uma revista como fonte de pesquisa para a História da Educação Matemática}

Um dos projetos desenvolvidos pelo grupo de pesquisa "A Matemática na organização curricular: história e perspectivas atuais"2, do Programa de Estudos Pós-graduados em Educação Matemática da PUC-SP, intenta mapear historicamente as relações entre matemáticos brasileiros e Educação Matemática ${ }^{3}$. Um dos objetivos desse grupo consiste na organização de documentos doados pelo professor Ubiratan D'Ambrosión, com vistas a seu aproveitamento como fontes de pesquisa. A organização, catalogação e higienização do

2 Um dos grupos de pesquisa existentes atualmente no Programa, coordenado pelos professores Célia Maria Carolino Pires, Ubiratan D'Ambrosio e Wagner Rodrigues Valente.

3 Projeto de pesquisa PUCSP/CNPq intitulado "Estudos sobre História da Educação Matemática no Brasil, 1950-2000" coordenado pelo Professor Doutor Wagner Rodrigues Valente.

4 Ubiratan D'Ambrosio, natural de São Paulo, obteve grau de licenciatura e bacharelado em Matemática pela FFCLUSP em 1954, grau de doutor em Matemática pela Escola de Engenharia de São Carlos em 1963, defendendo a tese "SuperfíciesGeneralizadaseConjuntosdePerímetro Finito", sob a orientação do Dr. Jaurès P. Ceccone e pós-doutorado em Brown University, USA, em 1965 (SILVA, 2003, p.145). Atualmente, é presidente da Sociedade Brasileira de História da Matemática; professor emérito de matemática da Universidade Estadual de Campinas; orienta alunos de pós-graduação em várias universidades do país e do exterior; membro do conselho da PUGWASH Conferences, movimento pacifista que ganhou o prêmio Nobel em 1995. É fundador do ISGEm/ International Study Group on Etnomathematics; membro do Conselho Científico do Museu de Astronomia e Ciências Afins/MAST do Ministério de Ciência e Tecnologia (D'AMBROSIO,2002). 
material doado pelo professor D’Ambrosio constituirá o APUA - Arquivo Pessoal Ubiratan D'Ambrosio ${ }^{5}$.

Durante os primeiros contatos com o material cedido pelo professor D’Ambrosio, despertou nossa atenção um fascículo da revista intitulada "Notas de Matemática e Física" datado de 1953. O fascículo trazia um artigo desse professor, quando ele ainda era estudante do Curso de Matemática. Encontrálo, em meio à grande quantidade de documentos do seu arquivo pessoal, feznos relembrar os dizeres Prochasson (1998), em artigo que trata das dificuldades e cuidados a serem tomados quando se trabalha com arquivos privados. Nele, Prochasson tomou como exemplo a história das revistas, para defender a necessidade de uma exploração sistemática desses arquivos, de modo a facilitar o trabalho daqueles que procuram entender os bastidores da vida cultural e política de uma época:

... as revistas se tomaram meios intelectuais, cuja observação informa sobre o funcionamento e a anatomia da vida cultural. Foi pela análise da revista fundada por Jean-Richard Bloch em 1910, L'Effort, que cheguei à sua correspondência, da qual uma parte importante é dedicada à vida da revista [grifo do autor] (1998, p.110).

Versando especificamente sobre revistas pedagógicas, Denice Catani (1996, p.115-130) elaborou um estudo sobre as potencialidades das revistas especializadas em educação de se estabelecerem como fonte para o estudo da constituição e da dinâmica do campo educacional numa perspectiva histórica. Em seu artigo, nos chama a atenção para aspectos até o momento pouco explorados pela História da Educação, quais sejam, a escrita de sua história centrada em configurações específicas da vida e da cultura escolar "que se apreende de maneira farta nos periódicos". Em suas ponderações, Catani (1996) ressalta a relevância dos periódicos pedagógicos como fontes específicas para a investigação dos modos de funcionamento do campo educacional, uma vez que fazem circular informações sobre o trabalho pedagógico e o aperfeiçoamento das práticas docentes.

Assim, interessou-nos investigar a vida dessa revista, partindo do pressuposto DE que revistas pedagógicas e científicas podem se tornar fontes importantes para as pesquisas que o grupo pretende realizar sobre a relação entre matemáticos e a Educação Matemática no Brasil.

5 Participam da elaboração do Inventário Sumário do APUA: Prof. Dr. Wagner Rodrigues Valente, organizador do projeto; a doutoranda Aparecida Rodrigues Silva Duarte; as mestrandas Rosemeiry de Castro Prado, Rosimeire Aparecida Soares Borges e os alunos de iniciação científica, Leila Mariana Pereira e Sidnei da Silva. 
Tomados pela curiosidade e entusiasmo, passamos a procurar mais informações sobre aquela revista. Desse modo, encontramos uma alusão a ela em artigo do próprio D'Ambrosio (2000, p. 7-12), "Da produção e difusão do conhecimento matemático", publicado nos anais do III Encontro Luso-brasileiro de História da Matemática, como também na obra "A Matemática no Brasil: História de seu desenvolvimento", de autoria de Clóvis Pereira da Silva (2003, p. 135) ${ }^{6}$.

Além disso, solicitamos uma entrevista com o professor D'Ambrosio, com o propósito de saber tudo que fosse possível a respeito da revista "Notas de Matemática e Física", no que fomos prontamente atendidos, apesar dos seus inúmeros compromissos.

Optamos por realizar uma entrevista parcialmente estruturada ${ }^{7}$, em que foram previamente elaboradas questões abertas, de modo a permitir ao entrevistado ampla liberdade para desenvolver cada situação da maneira que considerasse mais adequada, dentro de uma conversação informal.

A partir dos dados coletados na entrevista, procuramos estabelecer relações com aqueles obtidos por intermédio da análise dos fascículos da revista, extraindo algumas conclusões, ainda que parciais, com vistas ao desenvolvimento do trabalho de pesquisa focalizado, porquanto as muitas respostas às questões que se apresentam durante a fase de coleta de dados vão sendo encontradas na medida em que a prática e a dinâmica do trabalho vão se realizando (ZAGO, 2003).

Durante a entrevista, revelou-nos D’Ambrosio que, em 1953, era aluno do Curso de Matemática da Faculdade de Filosofia, Ciências e Letras da USP, estabelecido na Rua Maria Antonia, 294, no Bairro da Consolação. Na ocasião, os cursos de Matemática e Física eram ministrados, em conjunto, nas duas primeiras séries. A partir do 3.ํano, os currículos eram diferenciados, com poucas disciplinas em comum. Nos intervalos, professores e alunos reuniam-se no salão do grêmio estudantil, espaço reservado ao diálogo informal. Os assuntos, em sua maioria, eram gerais e versavam sobre educação, cultura, política. Os alunos do Curso de Matemática e Física, da turma ingressada em 1951, haviam conseguido, da direção da Faculdade, uma pequena sala, contígua ao Departamento de Matemática, reservada para seus estudos e encon-

6 Embora "Notas de Matemática e Física" tenha sido publicada nas dependências da FFCLUSP, em São Paulo, os exemplares dessa revista somente foram localizados na Biblioteca Professor Achille Bacci do ICMC- SC (Instituto de Ciências Matemáticas e de Computação de São Carlos/ SP).

7 Segundo Laville e Dionne, entrevistas parcialmente-estruturadas se caracterizam por temas particularizados e questões abertas preparadas antecipadamente; mas com plena liberdade quanto à retirada eventual de algumas perguntas, acréscimo de perguntas improvisadas e modificação na ordem em que essas perguntas foram elaboradas (1999, p. 188). 
tros. Ali, as discussões versavam, em geral, sobre as disciplinas do curso e também sobre o ensino secundário de Matemática e Física, bem como sobre suas práticas.

Um dos assuntos comentados na época tratava de temas trazidos no Boletim da Sociedade de Matemática de São Paulo, onde eram veiculados artigos sobre a ciência Matemática, os quais geralmente exigiam de seus leitores um prévio conhecimento de Matemática do nível superior. Eram, enfim, artigos cujos temas não se mostravam acessíveis aos alunos iniciantes no curso de Matemática. Faltava, pois, uma publicação mais dirigida aos alunos ingressantes na faculdade. Daí, por iniciativa dos alunos de Matemática e Física da FFCLUSP, surgiu a idéia de elaborar uma revista que contemplasse tanto alunos da graduação quanto professores secundários ${ }^{8}$.

Conta D'Ambrosio:

Ficamos sabendo que havia, na Faculdade Nacional de Filosofia, no Rio de Janeiro, uma revista que nos parecia ser aquilo que almejávamos. Era a "Revista Científica", com artigos principalmente de Matemática e Física. Conversamos e decidiu-se que eu iria ao Rio, aprender algo sobre essa revista. E assim fui à Faculdade Nacional de Filosofia, conversar com os alunos da Matemática. A revista era de outra natureza. Publicava artigos científicos, e era iniciativa de alguns professores jovens progressistas e se estimulava publicação por alunos. Mas não era o que tínhamos em mente. Se a viagem não ajudou muito na concepção da revista que idealizávamos, foi uma excelente oportunidade de encontrar colegas fazendo também o curso de Matemática. Éramos no mundo acadêmico, uns tipos estranhos. Falava-se: se gostam de Matemática, por que não vão fazer engenharia? Conhecer jovens cursando a FNF foi ótimo. Pudemos discutir programas, estilos de cursos [...]. Conheci vários colegas, alguns que depois tiveram e ainda têm grande influência em São Paulo, como Mário Tourasse Teixeira, Nelo da Silva Alan e Lafayete Morais.

Decidiu-se, assim, fazer uma revista original, com artigos cujos temas contribuíssem para atualização de seus conhecimentos, numa linguagem mais acessível, proporcionando uma ligação entre professores, alunos da FFCLUSP e outros alunos e professores do ensino médio. Mais ainda, era ambição dos alunos obter um espaço no qual pudessem publicar seus primeiros artigos científicos, como se pode inferir de seu "editorial":

8 Na década de 1950, após cursarem quatro anos do ensino primário e realizarem o exame de admissão, os alunos garantiam seu ingresso no ensino secundário. Com duração de sete anos, o curso secundário encontrava-se estruturado em dois ciclos: o primeiro, de quatro anos, chamado Ginasial e o segundo, de três anos, subdividido em Clássico e Científico, conforme previsto na Lei Orgânica do Ensino Secundário (Reforma Capanema), homologada em 9 de abril de 1942, pelo Decreto-lei no 4244 (CHAGAS, 1980, p. 115). 
“NOTAS DE MATEMÁTICA E FÍSICA” é a concretização das aspirações dos alunos da Faculdade de Filosofia, Ciências e Letras da Universidade de São Paulo, ansiosos por uma publicação especializada onde pudessem apresentar trabalhos, e, sobretudo, proporcionar aos professores secundários e aos colegas uma leitura que completasse os seus conhecimentos, mantendo-os sempre a par dos assuntos que lhes são de interesse (1953, p. 4).

Foi, portanto, por iniciativa dos alunos do Curso de Matemática e Física que surgiu a Revista "Notas de Matemática e Física”. Apenas três volumes foram impressos. O primeiro (Ano I, n. ${ }^{0}$ 1), de julho/setembro de 1953, contém oito artigos, seis deles de autoria dos professores da FFCLUSP e dois de alunos da mesma instituição. O segundo (Ano I, n.ํㅡ 2), de outubro/dezembro de 1953, contém cinco artigos, sendo apenas um deles de autoria de aluno da FFCLUSP. Dos artigos restantes, dois eram de professores do ITA (Instituto de Tecnologia da Aeronáutica) e dois de professores da FFCLUSP. A impressão da revista encerrou-se em maio de 1954. O terceiro e último volume (Ano II, no 3), de janeiro/dezembro de 1954, contém cinco artigos, todos de professores, sendo um deles assinado por professor do ITA (Instituto de Tecnologia da Aeronáutica), outro por professor da Escola Politécnica da USP e os três restantes por professores da FFCLUSP.

Para realização desse empreendimento, os estudantes do Departamento de Matemática e Física contaram com ajuda financeira dos professores da Faculdade de Filosofia. Além da contribuição pecuniária, os professores deram grande apoio aos alunos, formando, inclusive, seu corpo editorial, constituído pelos professores: Omar Catunda, Edison Farah, Cândido L da Silva Dias, Fernando Furquim de Almeida, Benedito Castrucci, Marcelo Damy S. Santos, Hans Stammreich, David Bohm, Mánio Schenberg, Oscar Sala e Abrahão de Moraes. 0 então diretor da Faculdade de Filosofia, Ciências e Letras da USP, Dr. E. Simões de Paula, facilitou a publicação, cedendo as gráficas da faculdade, onde foram compostos e impressos quinhentos exemplares dos dois primeiros volumes. $\mathrm{O}$ trabalho gráfico foi realizado em "off-set", que, segundo D'Ambrosio, representava uma técnica moderna para a época. Entretanto, não há referências sobre a quantidade de exemplares impressos do último volume. Ademais, contou com D’Ambrosio, aluno da Secção de Matemática, como sendo o seu diretor; Plínio Castrucci, Vice-Diretor; Iracema Martin, 1. Secretário; Amélia Império, 2. Secretário e Milton Damato, como 3.. Secretário. Zilah Castrucci, estudante de arquitetura, foi responsável pela capa e Herch Moisés Nussenzweig, aluno da Secção de Física, pelos desenhos inseridos nos textos. Em nossa entrevista, D'Ambrosio revelou que, apesar do cuidado estético e a preocupação com o seu conteúdo, não se pensou, em momento algum, em institucionalizar a revista. Todo o trabalho fora realizado sem nenhum tipo de contrato prévio para sua constituição, de modo a ficar caracterizada sua existência legal. 
Na Faculdade de Filosofia funcionava a sede da Sociedade de Matemática de São Paulo, responsável pela publicação de um boletim que levava o mesmo nome ${ }^{9}$, tendo como diretor de publicações o professor Luiz Henrique Jacy Monteiro ${ }^{10}$. Jacy Monteiro se colocou à disposição dos alunos, cedendo endereços de instituições no Brasil e no exterior, viabilizando a elaboração e distribuição de exemplares juntamente com cartões-resposta. Esses cartões visavam a correspondência com os leitores e possíveis permutas entre revistas.

O fato de D'Ambrosio ter sido o diretor da revista e de estarmos organizando seus documentos pessoais, faz-nos esperançosos de encontrar, dentre a massa de documentos em nosso poder, correspondências, fichas e endereços dessas instituições, os quais possam revelar novos aspectos, que ajudem a compor a análise das relações entre matemática e educadores matemáticos, finalidade última de nossa pesquisa.

\section{Dos autores e conteúdos}

O primeiro número das "Notas de Matemática e Física" foi inaugurado com um artigo de Omar Catunda"1 (1953, p. 05-10), intitulado "O ensino da Matemática na escola secundária". Nele, o então professor catedrático de Análise Matemática da FFCLUSP, faz um estudo sobre o ensino da Matemática no secundário. Pretendeu contribuir para responder à seguinte questão: Para que serve o ensino de Matemática? Assim se expressa a esse respeito:

O valor desse estudo reside não na matéria aprendida, mas no hábito adquirido de um processo de raciocínio puro, universal e absoluto; a mente que aprendeu uma vez esse processo de raciocínio, pode esquecer todas as fórmulas, regras e denominações estudadas, mas saberá, diante de um problema ou de uma situação real, discernir as premissas, simplificar ou esquematizar os dados e tirar as conclusões que se impõem, pelo menos em uma primeira aproximação da realidade (CATUNDA, 1953, p. 6).

9 O Boletim da Sociedade de Matemática de São Paulo publicou seu primeiro volume em 1946 e o último em 1966 (SILVA, 2003, p.135).

10 Luiz Henrique Jacy Monteiro (1918-1975), obteve grau de doutor em Ciências pela FFCLUSP em 1950, com a tese "Sobre as potências simbólicas de um ideal primo de um anel de polinômios", sob a orientação do professor Oscar Zariski (1899-1986).

11 Omar Catunda (1906-1986), representante e divulgador da escola matemática introduzida no Brasil pelo italiano Luigi Fantappiè (1901-1956), de quem foi assistente e colaborador na implantação do departamento de matemática da FFCLUSP, a partir de 1934. Merece destaque sua contribuição para a formação de diversas gerações de matemáticos e físicos; como também sua atuação pedagógica relativa ao ensino básico, tornado-se um dos precursores da educação matemática brasileira (DIAS, 2001, p.40). 
Defende, como princípio fundamental, um ensino de Matemática todo baseado no raciocínio. Afirma, enfaticamente, que a "Matemática é raciocínio", ou seja, é o culto ao bom senso, no qual "todo professor dessa matéria deveria ter em mente" (CATUNDA, 1953, p. 6). A adoção e fidelidade a esse princípio evitariam, segundo Catunda, erros comuns que ocorrem nas escolas brasileiras, como o de procurar incutir nos alunos uma variedade de regras e fórmulas sem que os alunos percebam sua razão de ser.

Em seguida, Catunda fez referências ao ensino da Geometria e Álgebra. Indica, para essas áreas, alguns procedimentos desejáveis aos professores e organizadores de programas de Matemática de modo a obter uma melhoria do seu ensino no secundário.

O ensino da Geometria precisaria ser introduzido pelas formas mais elementares e esquemáticas a partir de exemplos concretos, pois, para Catunda, é pela observação e experiência que melhor se conduz o aluno a aceitar os postulados sobre pontos, retas e planos, dos quais se deduzem todas as outras proposições geométricas. A Geometria, assegura o professor Catunda, é a área que melhor se presta ao desenvolvimento do raciocínio lógico:

Éno estudo da Geometria que tradicionalmente se introduzem explicitamente as noções lógicas de proposição, teorema, corolánio, hipótese, tese, etc. (...) bem conduzido o ensino, com constantes referências a exemplos concretos e freqüentes exemplos de aplicação, como os problemas de construção com régua e compasso, obtêm-se certamente um desenvolvimento notável de capacidade de raciocínio. Para isto é porém necessário que o professor não se restrinja à exigência de regras decoradas e fórmulas de cálculo de comprimento de segmentos e de áreas de figuras planas, que só servem para encher a cabeça dos pobres alunos, e dedique o melhor de seu esforço para conseguir que os alunos compreendam o desenvolvimento do raciocínio em todas as fases (CATUNDA, 1953, p. 9).

No que diz respeito à Aritmética, deveria o ensino secundário conservar o mais possível sua feição concreta, com grande quantidade de exemplos, de modo a convencer o aluno da necessidade das regras e fórmulas dadas:

Com exemplos concretos, acumulados e repetidos, é perfeitamente possível ao professor conduziro raciocínio dos alunos de modo a fazê-los aceitar como fato evidente por si mesmo, e não pelo falso princípio do "magister dixit", a justeza das regras e fórmulas deduzidas [grifo do autor] (CATUNDA, 1953, p. 8).

Como se pode observar, o primeiro artigo da revista fez referência justamente ao ensino da Matemática na escola secundária, mostrando uma preocupação por parte de alunos e docentes de nível superior com a melhoria 
do ensino de Matemática no secundário. Além disso, o professor Catunda, ao propor sugestões nas diversas áreas que compõem a Matemática, pareceu buscar convencer os professores do ensino secundário a utilizar novos métodos de ensino, de modo a conduzir ao desenvolvimento do raciocínio "puro, universal e absoluto" dos alunos em todas as fases.

O primeiro exemplar contém, ainda, os seguintes artigos: "Comparação entre a física no Brasil e nos Estados Unidos", de David Bohm; "Sobre as equações das bissetrizes de um triângulo", de Edison Farah; "Determinação analítica elementar do raio refletido e do raio refratado", de Rômulo Ribeiro Pieroni; "Os precursores da Mecânica Newtoniana", de Herch Moysés Nussenzveig; "Triângulos com duas bissetrizes iguais são isósceles", de Ubiratan D’Ambrosio e "Um aparente paradoxo na mecânica elementar", de Klaus S. Tausk.

No artigo assinado por Herch Moysés Nussenzveig (1953, p. 37-65), então aluno da Secção de Física da FFCLUSP, denominado "Os precursores da Mecânica Newtoniana", o autor esclarece que o artigo constituiu a matéria de um seminário da série organizada pelo professor Shigueo Watanabe sobre questões de Dinâmica dos Sistemas Materiais. Nussenzveig também defende a necessidade da Faculdade de Filosofia oferecer aos seus alunos um curso de História das Ciências, sugerindo, enquanto não implantado, uma medida paliativa:

Enquanto não tivermos uma cadeira de História da Ciência, o jeito é tratar de remediar, nós mesmos, essa situação. Felizmente, há algo que nos pode prestar um auxílio inestimável: a leitura das obras originais dos grandes clássicos da ciência. [...] Com efeito, em nenhum outro lugar os conceitos básicos aparecem com tanta clareza, os argumentos com tanto vigor e profundidade, como nessas obras. É nelas que vemos o papel preponderante desempenhado pela intuição nos descobrimentos e, principalmente, a influência que neles exercem as idéias e necessidades sociais de cada época.

Nesse artigo, o autor procurou analisar os primórdios da História da Mecânica, desde as origens até o século XVII, examinando as contribuições mais relevantes para o desenvolvimento da Mecânica antes de Newton.

Nussenzveig manifestou sua opinião sobre uma possível modificação no currículo do Curso de Matemática e Física. Vê-se, portanto, que a revista também era vista como um espaço no qual os alunos poderiam expressar suas pretensões quanto ao andamento do curso e mesmo sugerir mudanças.

Ubiratan D’Ambrosio, nessa época, ainda era aluno da Secção de Matemática da FFCLUSP e, como já dito, diretor da revista "Notas de Matemática e Física". Em seu artigo denominado "Triângulos com duas bissetrizes iguais são isósceles" (1953, p. 66-72), relata como foram elaboradas algumas demonstrações relativas ao teorema: "triângulos com duas bissetrizes iguais 
são isósceles". Obedecendo a uma ordem cronológica, comentou brevemente sobre os matemáticos que estudaram o problema, descrevendo a demonstração realizada e indicando qual a fonte utilizada durante a pesquisa. Esclareceu, também, que a idéia de pesquisar a respeito desse teorema e buscar quais os matemáticos se preocuparam em demonstrá-lo, surgiu durante um seminário realizado na Secção de Matemática, quando o professor Omar Catunda elaborou uma demonstração do mencionado problema. Intrigado, D’Ambrosio buscou na literatura produzida a respeito, por meio de uma pesquisa histórica, elementos que subsidiassem maiores esclarecimentos sobre esse teorema.

D’Ambrosio iniciou com a proposta de L. Lehmus, em 1840, dirigida a J. Steiner, instigando-o a encontrar uma solução elementar para a proposição "Triângulos com duas bissetrizes iguais são isósceles". Steiner encontrou uma demonstração baseada no raciocínio por redução ao absurdo, que foi publicada no periódico "Crelle's Journal"12. Relatou D’Ambrosio, em seu artigo, que, em 1880, apareceu no "Journal de Mathématiques élémentaires e spéciales" uma outra, de autoria de J. Descube, mais simples, utilizando também este mesmo procedimento (1953, p. 67). Segundo D'Ambrosio, a primeira demonstração direta apareceu em 1931, no "Periódico di Matematiche", apresentada pelo engenheiro Nicola Romeo. Este mesmo engenheiro, nos idos de 1937, apresentou, na mesma revista, outra demonstração do mesmo teorema.

D’Ambrosio finaliza seu relato apresentando a demonstração desse teorema idealizada pelo professor Catunda:

Recentemente o professor Omar Catunda comunicou-nos o seguinte teorema, bastante geral: "Tomando sobre a bissetriz de um ângulo um ponto, e dois segmentos passando por esse ponto e com extremos nos lados do angulo, 0 segmento que tiver um extremo mais próximo do vértice do ângulo será 0 maior" (1957, p. 70).

Após a demonstração do teorema acima citado, o autor apresentou o seu corolário, que traz como conseqüência a demonstração inicialmente proposta, qual seja, considerando um triangulo $\mathrm{ABC}$, se os segmentos $\mathrm{AD}$ e $\mathrm{BE}$ se cortam num mesmo ponto sobre a bissetriz do ângulo do vértice, e são iguais, o triângulo $\mathrm{ABC}$ é isósceles. Como auxiliar à demonstração, D’Ambrosio valeu-se de cinco notas explicativas que completam a demonstração.

12 August Leopold Crelle (1780-1855) inaugurou, em 1826, o "Journal für die reine und angewandte Mathematik", mais conhecido como "Journal de Crelle". O Journal de Crelle é parte importante do desenvolvimento da ciência de seu tempo, particularmente da Matemática. Crelle tinha um dom extraordinário para julgar as qualidades dos jovens talentos e por encorajá-los em suas pesquisas. Abel, Dirichlet, Eisenstein, Grasmann, Hesse, Jacobi, Kummer, Lobachevski, Möebius, Plücker, V. Staudt, Steiner e Weierstrass tiveram seus primeiros trabalhos conhecidos por intermédio do Jornal de Crelle (FRIEDELMEYER, 1995, p.231). 
Esse artigo revela, da parte de D'Ambrosio, um certo interesse pela História da Matemática. Não obstante, na entrevista, nos afirmou que tal interesse era inconsciente, muito embora manifestasse, desde a infância, entusiasmo pela pesquisa em documentos históricos.

$\mathrm{O}$ artigo mostra, ainda, que a revista dispunha de certo potencial para se tornar mais um importante veículo na troca de informações sobre experiências realizadas pelos professores dos cursos de Matemática e Física, disponibilizando-as aos colegas de outras instituições do Brasil e do exterior, já agora com a participação dos próprios alunos na divulgação do resultado das pesquisas, proporcionando o envolvimento dos estudantes no processo de produção científica.

O volume número 2, das "Notas de Matemática e Física", publicou os seguintes artigos: "Nota sobre a congruência de ângulos", de Benedito Castrucci; "As escalas usuais de temperatura e a solução Giauque", de Rômulo Ribeiro Pieroni; "Seqüência de matrizes N x 1", de Nelson Onuchic; "Uma maneira simples de traçar Lissajous", de Newton Bernardes e "Estudo da nésima potência de uma soma de r elementos", de Gilberto Loibel.

O artigo apresentado por Loibel (1953, p. 27-36) trouxe algumas considerações iniciais, nas quais observamos serem destinadas ao ensino secundário, pois indicou quais os pré-requisitos necessários para o entendimento do estudo em questão:

Este estudo exige somente o conhecimento das noções fundamentais se análise combinatória e do binômio de Newton. Em algumas partes foi utilizado o livro: F. Severi "Lezioni de Analisi I".

O estudo que faremos será em torno da expressão $\left(a_{1}+a_{2}+\ldots a_{r}\right)^{\mathrm{n}}$ e abordará as três seguintes questões: 1) cálculo dos coeficientes; 2) distribuição dos termos segundo o número de elementos; 3 ) cálculo do número de coeficientes (1953, p. 27).

Comentários desse tipo, sobre pré-requisitos necessários para leitura, não foram observados nos outros artigos que integram o periódico.

O terceiro volume apresenta os seguintes artigos: "Sistemas de equações lineares", de Fernando Furquim de Almeida; "Sobre uma aplicação do teorema do Valor Médio", de J. A. Breves Filho; "Ensaios simples de elasticidade", de R.M. Otto Weinbaum; "Notação de Gullstrand", de Rômulo Ribeiro Pieroni e, por fim, "O planejamento de experiências físicas”, de José Goldemberg.

Na introdução do tema "Sistemas de equações lineares", o professor Furquim de Almeida, expôs suas razões para apresentar um método de resolução de sistemas que independe da teoria dos determinantes. Assim se manifestou: 
Entre nós está bastante difundida a resolução pormeio de determinantes. Esse método não é, em geral, o mais prático, sendo mesmo, a nosso ver, o mais complicado. Essa é a razão deste artigo, no qual expomos um outro processo de resolução sem o uso de determinantes. Éum processo conhecido, de modo que o único mérito deste artigo é difundi-lo entre nós.

Temos a convicção que é o mais simples e que poderia ser ensinado nos colégios com proveito. Entre as vantagens teóricas cumpre assinalar a sua independência da teoria dos determinantes tão pouco do agrado dos alunos. Quanto à prática, se o leitor aplicá-lo verá que temos razão em tudo que dissemos acima (ALMEIDA, 1954, p. 5).

Infere-se desse diálogo com o leitor, que o professor Furquim mostrou preocupação com a difusão de métodos mais adequados ao ensino de sistemas de equações lineares, buscando facilitar a compreensão desse assunto pelos alunos do ensino médio. Nos outros artigos do volume 3, apenas Otto Weinbaum (1953, p. 15-17), em seu artigo "Ensaios simples de elasticidade", fez uma explanação voltada ao aluno secundarista: "Para explicar ao aluno do ginásio que há proporcionalidade entre carga e deformação dentro da zona considerada elástica de um material pode-se executar o seguinte ensaio [...]" (1953, p. 15). Há, desse modo, uma preocupação dos professores, que colaboram com artigos na revista, em sugerir a utilização de novos métodos de resolução que facilitem o aprendizado dos alunos do ensino secundário.

Os volumes da revista "Notas de Matemática e Física" traziam uma "Secção de Problemas" na qual, em princípio, foram propostos quatro problemas, sendo dois de Matemática e dois de Física. Para cada uma das áreas consideradas, de acordo com os recursos necessários para a resolução dos problemas apresentados, as primeiras questões eram indicadas para o ensino secundário e as segundas voltadas para o ensino superior. E ainda:

Cada número trará as soluções dos problemas propostos no anterior. A solução escolhida obedecerá aos seguintes critérios:

1) Será publicada a mais original dentre as enviadas pelos leitores, publicando-se ainda os nomes de todos os que acertaram;

2) A da revista, no caso de não haver nenhuma solução dos leitores ou de não serem satisfatórias, as enviadas (1953, p. 77).

Vê-se, dessa forma, que a revista tinha uma postura desafiadora, e, ao mesmo tempo, buscava incentivar seus leitores a participarem de sua elaboração, pois esses poderiam enviar suas respostas aos problemas propostos, com possibilidade de verem seus nomes divulgados nos números seguintes.

Não obstante os esforços para motivar seus leitores, apareceu no segundo volume do "Notas de Matemática e Física", o seguinte comentário: 
Talvez por não termos esclarecido suficientemente os leitores, não recebemos a colaboração desejada, principalmente quanto à resolução dos problemas. Repetimos que uma das finalidades de NOTAS DE MATEMÁTICA E FÍSICA é acolher, na medida do possível, colaboração de estudiosos. Resolvemos não publicar a Secção de Problemas neste número, na esperança de recebermos ainda as soluções anteriores [grifo dos autores] (1954, p .3).

A "Seç̧ão de Problemas" reaparece no terceiro volume, apresentando quatro novos problemas e com as soluções daqueles propostos anteriormente, sendo que o primeiro problema de Matemática fora resolvido pelo leitor Rubens Betelman, que teve, dessa forma, seu nome publicado na revista (1954, p. 46-52).

Além da "Secção de Problemas", a revista trazia, ainda, uma seção intitulada "Notícias e Comentários", também com a intenção de manter correspondência com os leitores, que poderiam enviar consultas e sugestões aos redatores. Nela, apareceram frases de ilustres matemáticos, curiosidades, cursos que foram ou seriam ministrados e respostas às solicitações efetuadas pelos leitores (1954, p. 45).

Em artigo publicado em Coimbra, D'Ambrosio comentou sobre a importância das "Notas de Matemática e Física" que, além de procurar tornarse um elo entre pesquisa e ensino, apresentou-se como um dos primeiros sinais do movimento da Matemática moderna que surgiria na década seguinte:

Na verdade, apareceram mais trabalhos de professores que de alunos. Mas é mantido um nível de originalidade, procurando-se a integração entre pesquisa e temas de interesse didático. Pode-se dizer que a preocupação dos alunos foi compartilhada pelos professores, então catedráticos e assistentes. Pode-se interpretar essa preocupação dos pesquisadores com questões didáticas como um precursor do seu importante envolvimento com 0 movimento da Matemática moderna em São Paulo, na década de 60 (2000, p. 7-12).

O professor D'Ambrosio lembrou em sua entrevista que, para o quarto número, havia a promessa de Mário Bunge ${ }^{13}$ de mandar para a revista um artigo sobre "Filosofia da Probabilidade". Esse fato, acrescentado às publicações dos renomados professores que se prontificaram a colaborar com a revista, e ainda à quantidade de exemplares impressos, vem confirmar, segundo D'Ambrosio, a importância que o periódico teria, caso os alunos tivessem dado continuidade ao trabalho.

13 Mário Bunge (1919-), pensador argentino que se destacou como historiador e filósofo da ciência, autor de diversas obras, dentre as quais "Dicionário deFilosofia" e "Filosofia da Física" (1997). 
O quarto fascículo não saiu. D'Ambrosio continuou seu relato, mencionando que os alunos responsáveis pela produção e publicação da revista estavam preocupados com a chegada da formatura e a proximidade do concurso para o magistério, que, na época, já era bastante concorrido. "Notas de Matemática e Física" era uma revista de alunos, com suporte técnico-teórico da administração da faculdade. O pecado fora não envolver os outros alunos ingressantes, para que dessem continuidade ao trabalho. Ingenuamente, não se pensou ser necessário empenho no sentido de incentivar os novatos para assumirem a produção, tampouco houve a preocupação em sensibilizar os professores para assumirem esta responsabilidade. Era uma revista de estudantes que, enquanto existiu, foi um sucesso. No entanto, aquele ideal não fora encampado pelas outras turmas. Finalizando, lembrou D'Ambrosio, que a revista, idealizada por uma turma, organizada e publicada por essa mesma turma, acabou por extinguir-se com ela, no ano em que aqueles jovens se formaram.

\section{Considerações finais}

A Revista "Notas de Matemática e Física" foi fruto da realização levada a cabo pelos alunos do Curso de Matemática e Física. A idéia era fazer quatro publicações anuais. No entanto, a revista teve seus dois primeiros números publicados em 1953 e um terceiro e último número em 1954. As "Notas de Matemática e Física" não vingaram, muito embora tivessem tido a colaboração e participação de renomados professores de Matemática e Física.

O término da faculdade e a necessidade de se lançarem ao mercado de trabalho, participando de concursos públicos, provocaram mudanças no foco de interesse dos alunos responsáveis por esse empreendimento, desestimulando-os na continuidade desse trabalho. Além disso, outros alunos, aqueles iniciantes na FFCLUSP, não se preocuparam em dar prosseguimento ao trabalho dos colegas que estavam prestes a deixar a universidade. Isso vem confirmar que as influências de fatores sócio-econômicos e culturais tanto podem contribuir para a continuidade e desenvolvimento de um projeto, como provocar sua inviabilização, tal como ocorreu com as "Notas de Matemática e Física".

A revista acabou por abrir um espaço editorial para estudantes e professores, permitindo uma troca de experiências entre aquelas esferas de atuação. As correspondências que seus redatores pretenderam manter nas "Secções de problemas" e "Notícias e comentários" revelaram o propósito de cultivar um intercâmbio entre professores do ensino secundário e alunos e professores do ensino superior, mostrando que possuíam como preocupação 
comum, além da intenção de fornecer uma atualização dos conhecimentos matemáticos, o interesse pela pesquisa nas áreas da Matemática e Física, e, ainda, a preocupação com questões didáticas. A revista proporcionou, assim, um canal aberto para o diálogo entre o ensino secundário e superior, buscando a interação entre ensino e pesquisa.

"Notas de Matemática e Física" demonstrou a importância de serem realizados inventários dos periódicos didático-pedagógicos, por meio dos quais podemos colher novas informações, que nos permitam avançar na tentativa de compreender as relações travadas ao longo da história entre matemáticos brasileiros e suas preocupações com o ensino elementar.

\section{Referências}

BUNGE, Mário. Filosofia da Física, 1997. Disponível em: <http:// www.edicoes70:pt/edicoes70/livro.asp?id=745>. Acessado em: 05 jan 05.

CATANI, Denice B. A imprensa periódica educacional: as revistas de ensino e o estudo do campo educacional. Educação e Filosofia, v. 10, n. 20, p. 115-130, jul./dez. 1996.

CHAGAS, V. Educação Brasileira: o ensino de $1^{0}$ e $2^{\circ}$ graus: antes, agora e depois? 2. ed. São Paulo, SP: Saraiva, 1980.

D’AMBROSIO. Ubiratan. São Paulo, SP: jul, 2003. Entrevista concedida a Aparecida Rodrigues Silva Duarte.

. Da produção à difusão do conhecimento matemático. In: ENCONTRO LUSSO-BRASILEIRO DE HISTÓ RIA DE MATEMÁTICA. 3., 2000. Anais... Coimbra, Disponível em: <http://vello.sites.uol.com.br/coimbra.htm>. Acesso em: 20 jun. 2003.

. EtnoMatemática: elo entre as tradições e a modernidade. 2 ed. Belo Horizonte: Autêntica, 2002.

DIAS, André Luis M. Omar Catunda: alguns aspectos de sua trajetória e da suas concepções científicas e educacionais. História \& Educação Matemática, v. 1, n. 1, p. 38-48, jan./jun. 2001.

A revista brasileira de mathematica 1929-1932. In: SEMINÁRIO NACIONAL DE HISTÓRIA DA MATEMÁTICA, 4., 2001. Natal. Anais... Natal: UFRN. 2001. p. 68-77.

FRIEDELMEYER, Jean- Pierre. La création des premières revues de Mathématiques et la distinction Mathématiques pures, Mathématiques 
appliquées. Actes de la 6⿳一巛工 Université d’Été interdisciplinaire sur l'historie des mathématiques. Contribuition à une approche historique de l'enseignemant des mathématiques. Université de Franche-Comté. Besançon: IREM. 1995, p. 214236.

LAVILLE, Christian; DIONNE, Jean. A construção do saber: manual de metodologia da pesquisa em ciências humanas. Porto Alegre: Artes Médicas, 1999.

INAUGURAÇÃO DO ANFITEATRO LUIZ HENRIQUEJACY MONTEIRO. Produção da Universidade de São Paulo. São Paulo, SP: Instituto de Matemática e Estatística da Universidade de São Paulo, 1993. 1 Videocassete, (90 min): VHS, son., color.

FACULDADE DE FILOSOFIA, LETRAS E CIÊNCIAS HUMANAS. Notas de Matemática e Física 1953-1954. São Paulo, SP: FFLCH/USP. 1954.

PROCHASSON, C. Arquivos privados e renovação das práticas historiográficas. Tradução de Dora Rocha. Estudos Históricos, Rio de Janeiro, n. 21, p. 105109, 1998.

SILVA, Clovis Pereira da. A matemática no Brasil: história de seu desenvolvimento. 3. ed. São Paulo, SP: Edgar Blücher, 2003.

VALENTE, W. R. (Coord.). Estudos sobre história da educação matemática no Brasil, 1950 - 2000. São Paulo, SP: CNPq. 2003.

ZAGO, Nadir. A entrevista e seu processo de construção: reflexões com base na experiência prática de pesquisa. In: ZAGO, Nadir; CARVALHO, Marilena Pinto; VILELA, Rita Amélia. Itinerários de pesquisa: perspectivas qualitativas em sociologia da educação. Rio de Janeiro, RJ: DP\&A. 2003.

Recebido em: 05/04/2005. Aprovado em: 20/06/2005. 